\title{
Insights into low biological activity of wax apple (Syzygium samarangense) juice by in vitro phytochemical investigation with special reference to metabolomics
}

\author{
SOUMYA MAJUMDER, SUKANYA ACHARYYA, ARINDAM GHOSH, SOURAV CHAKRABORTY, \\ SAHADEB SARKAR, SUMEDHA SAHA, MALAY BHATTACHARYA \\ Molecular Biology and Tissue Culture Laboratory, Department of Tea Science, University of North Bengal. Siliguri 734013, India. \\ Tel.: +91-9832094875, `email: malaytsnbu@gmail.com.
}

Manuscript received: 2 April 2021. Revision accepted: 28 May 2021.

\begin{abstract}
Majumder S, Acharyya S, Ghosh A, Chakraborty S, Sarkar S, Saha S, Bhattacharya M. 2021. Insights into low biological activity of wax apple (Syzygium samarangense) juice by in vitro phytochemical investigation with special reference to metabolomics. Biofarmasi J Nat Prod Biochem 19: 30-38. Wax-apple (Syzygium samarangense) is an Asian waxy and juicy fruit that is reported as antidiarrheal and useful in diseases like dysentery. Moreover, no stronger medicinal evidence has been found associated with this fruit and its juice to ensure more biological activities and composition. Being edible, waxy and juicy, this fruit is quite popular in coastal areas and islands, but the absence of stronger medicinal and biochemical evidence associated with this fruit or its juice has created a worldwide underutilizing status. In this research, we intended to investigate phytochemical characteristics and composition of this fruit juice through detailed biochemical tests and metabolomics. Qualitative detection tests for bioactive groups of molecules (tannin, coumarin, cardiac glycosides, terpenoids, flavonoids, phenol, etc.), antioxidant assay, and antibacterial test simply showed its low in vitro biological activity. A GC-MS based metabolomics was performed where presence of wax components like long-chain hydrocarbons has been revealed. Based on the GC-MS based metabolomics a proposed pathway of wax apple's wax biosynthesis has been established. The overall study strongly clarified the absence of bioactive components in this fruit and proved that the fruit, named wax apple, is actually a source of natural waxes that can be responsible for its claimed antidiarrheal property.
\end{abstract}

Keywords: GC-MS analysis, hexadecane, Java apple, metabolomics, Syzygium samarangense, wax

Abbreviations: WAJ: Wax apple juice; GC-MS: Gas Chromatography-Mass Spectrometry, DPPH: 2,2-diphenyl-1-picrylhydrazyl, DBP: Dibutyl phthalate

\section{INTRODUCTION}

Wax apple is an underutilized waxy tropical fruit commonly called Java apple, samarang rose apple, jambu semarang (Indonesia) and jamrul in Bengal (India), also known as, jambu ayer rhio (Malaya), pini jambu (Ceylon), chom pu kao, or chom pu kio (Thailand), makopa (Philippines), cashu di Surinam, or Curacaose appel (Curacao), wax jambu and water apple (Morton 1987; Lim 2012). The fruit is usually white or light-red, sometimes greenish-white or cream-colored, pear-shaped, narrow at the base and flattened with fleshy calyx lobes at the apex. The skin of the fruit is very thin; the flesh is white, spongy and dry to juicy, slightly acidic and flavorless. The fruit is usually eaten fresh but is also used in salads. In Thailand, it is most popular in addition to spicy shrimp salad (Fruitsinfo 2021). In Malaya, the greenish ones are eaten raw with salt or may be cooked as a sauce or stewed with true apples (Morton 1987). The wax apple tree is an evergreen tree (5$15 \mathrm{~m}$ tall) growing only at the lower altitudes up to $1,220 \mathrm{~m}$ in India (Morton 1987). According to WCSP (2021) (Royal Botanic Gardens, Kew) wax jambu is identified as Syzygium samarangense (Blume) Merr. \& L.M.Perry, J. Arnold Arbor. 19: 115 (1938) belonging to the family Myrtaceae.
The tree is indigenous in Asia from Malaya to the Andaman and Nicobar Islands. It is widely found in the Philippines islands, Thailand, Cambodia, Laos, Vietnam, Taiwan, India and Bangladesh. Now it is also very popular in the places like Jamaica, Suriname and the islands of Curacao, Aruba and Bonaire, etc. Khandaker and Boyce (2016) studied the Botany of wax apple in-depth in a review article where three edible cultivars of wax apple were described viz. 'Masam manis pink', 'Jambu madu red' and 'Giant green' cultivar from south Asia. Giant green cultivar is the greenish-white wax apple (creamy white when ripen), also known as white wax apple or 'Jamrul' (mainly grown in sub-Himalayan plains of West Bengal, India) was chosen for this study. The complete distribution of these cultivars (both native and exotic ranges) has been reported in that article where regions of Southeastern Asia (sub-mountain plains of eastern Himalayas) have been stated. Jambu madu red (red wax apple) and Masam manis pink (pink wax apple) are reported to be native to Malay region (Khandaker and Boyce 2016).

This tropical plant and its fruit are reported to be useful in diseases like dysentery, amenorrhea, diabetes, cough, headaches, and fever. A compound named vescalagin, which was isolated from fruits of Syzygium samarangense, showed hypoglycaemic activity (Shen et al. 2013). According to 
Ghayur et al. (2006), Reynertson et al. (2008) and Shen et al. (2013) the fruits can exhibit antidiarrheal activities. Not only the fruits but other parts of jamrul plant as well have reported health benefits. The leaf extract revealed immunomodulatory, analgesic and anti-inflammatory and anti-hyperglycemic effects as well as analgesic, antiinflammatory and CNS activities (Kuo et al. 2004; Amor et al. 2004; Shahreen et al. 2011; Resurreccion-Magno et al. 2005) whereas the astringent bark is used as mouthwash, abortifacient as well as in diarrhea, helminthiasis, etc. (Morton 1987). The ethanolic extract of bark of this tropical showed dose dependent anthelmintic activities (Gayen et al. 2016). Interestingly, flowers of this plant are astringent and used in Taiwan to treat fever and halt diarrhea (Morton 1987; Mollika et al. 2014). Bioactive compounds like triterpenoids and chalcone were also reported in aerial parts of Syzygium samarangense (Srivastava et al. 1995).

Though there are several reports on ethnomedicinal use of java apple, but investigations and identification of compounds in its fruit juice (main edible part of the plant) by chromatography technology and metabolomics have not yet been conducted. Even, to date, biochemistry didn't reveal the reason why the word "wax" is used with the name of this fruit. So, to meet up these lacunae, our research was designed to study the phytochemical profile of this fruit juice with in vitro biochemical experiments.

\section{MATERIALS AND METHODS}

\section{Collection of sample and its preparation}

Matured creamy-white colored wax apple fruits ("Jamrul" in West Bengal, India and Bangladesh) were harvested from a matured plant in Jayantika Tea Estate,

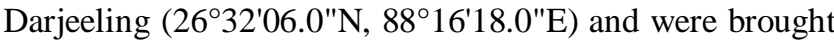
fresh to laboratory for downstream experiments (Figure 1). A herbarium specimen was also prepared and deposited in Kalimpong College Herbarium (Voucher no. KPGC/MB/90) where a proper identification of the fruit (White wax apple or Syzygium samarangense (Blume) Merr. \& L.M. Perry) was done by botanists of Kalimpong College (West Bengal). After collection fresh fruits were washed under running cold water to remove dust and were rubbed with blotting paper to remove water from its surface. Selected healthy fruits were crushed and squeezed properly to separate the juice (Figure 1) completely from the pulp. Wax apple juice (WAJ) was then filtered and used in further study.

\section{Qualitative chemical tests}

Qualitative detection tests for bioactive groups of molecules like tannin, coumarin, cardiac glycosides, steroid, terpenoids, flavonoids, phenol, proteins, starch and reducing sugar in WAJ were done using the protocols of Ghosh et al. (2020) and Das et al. (2020) (Table 1).

\section{Antioxidant activity (DPPH assay)}

Antioxidant or free radical scavenging activity by DPPH assay was conducted following the protocol of Bhattacharya et al. (2009) with slight modifications. To $2800 \mu \mathrm{L}$ of the methanol solution of $0.2 \mathrm{mM}$ DPPH (SRL, India), $200 \mu \mathrm{L}$ of WAJ was added. The mixture was vortexed vigorously and incubated at room temperature for 30 minutes in dark. Absorbance was measured at $517 \mathrm{~nm}$ by UV-Vis spectrophotometer. DPPH scavenging activity was measured as $\mu \mathrm{g} \mathrm{AAE} / \mathrm{mL}$ (ascorbic acid equivalent) because ascorbic acid was used to prepare the standard curve to quantify the antioxidant value. Result is given as means of total of five replications.

\section{Antibacterial test}

Antibacterial activity of WAJ was tested by well diffusion method following Ghosh et al. (2020) and Das et al. (2020). Overnight grown broth culture of two gram positive (Staphylococcus aureus and Bacillus cereus) and two gram negative (Escherichia coli and Klebsiella pneumoniae) bacteria were used for the present study to assess the antibacterial activities of synthesized samples. Mueller-Hinton (MH) agar media (HiMedia) was used for this test. The media was autoclaved and plated under sterile conditions in laminar air flow cabinet. $100 \mu \mathrm{L}$ of bacterial strains were added separately to each plate containing media. Circular wells were dug out by sterilized steel corkborer. $100 \mu \mathrm{L}$ of each WAJ was poured into the well by using sterilized pipettes. The plates were incubated overnight at $37{ }^{\circ} \mathrm{C}$ for 24 hours.

\section{GC-MS based metabolomics}

Fresh jamrul juice or WAJ $(1 \mathrm{~mL})$ was dissolved in $1 \mathrm{~mL}$ methanol (Sigma Aldrich, Germany) prior for GC-MS analysis following the protocol of Majumder et al. (2020) and Chakraborty et al. (2021). Being widely used ideal solvent in phytochemistry compared to another organic solvent, methanol was chosen for extraction. Moreover, polarity of methanol as an organic solvent shows closeness with that of water (primary solvent of any fruit juice). GCMS-QP2010 Plus (Shimadzu Co., Japan) was used in this analysis where DB-5 fused-silica capillary column $(0.25 \mu \mathrm{m}$ film thickness, $0.25 \mathrm{~mm}$ internal diameter and $30 \mathrm{~m}$ of length). Analysis was performed by injecting $1 \mu \mathrm{L}$ each sample with a split ratio of 20:1. Injection temperature was $260^{\circ} \mathrm{C}$ and interface temperature was set to $270^{\circ} \mathrm{C}$. Ion Source temperature was adjusted to $230^{\circ} \mathrm{C}$. Helium gas (99.9\%) was used as carrier gas. Total flow rate and column flow rate were $16.3 \mathrm{~mL} / \mathrm{min}$ and $1.21 \mathrm{~mL} / \mathrm{min}$ respectively. Mass spectra were recorded at $5 \mathrm{scan} / \mathrm{sec}$ with a scanning rate of $40-650 \mathrm{~m} / \mathrm{z}$. The compounds were identified after comparing the spectral configurations obtained with that of available mass spectral database. The compounds were detected using library databases like NIST08s.LIB and WILEY8.LIB. The chromatogram (TIC or Total Ion Chromatogram) is based on the intensity of fragments produced by the ionization. Quantification of the amount (area \%) of each compound was done on the basis of peak areas. 

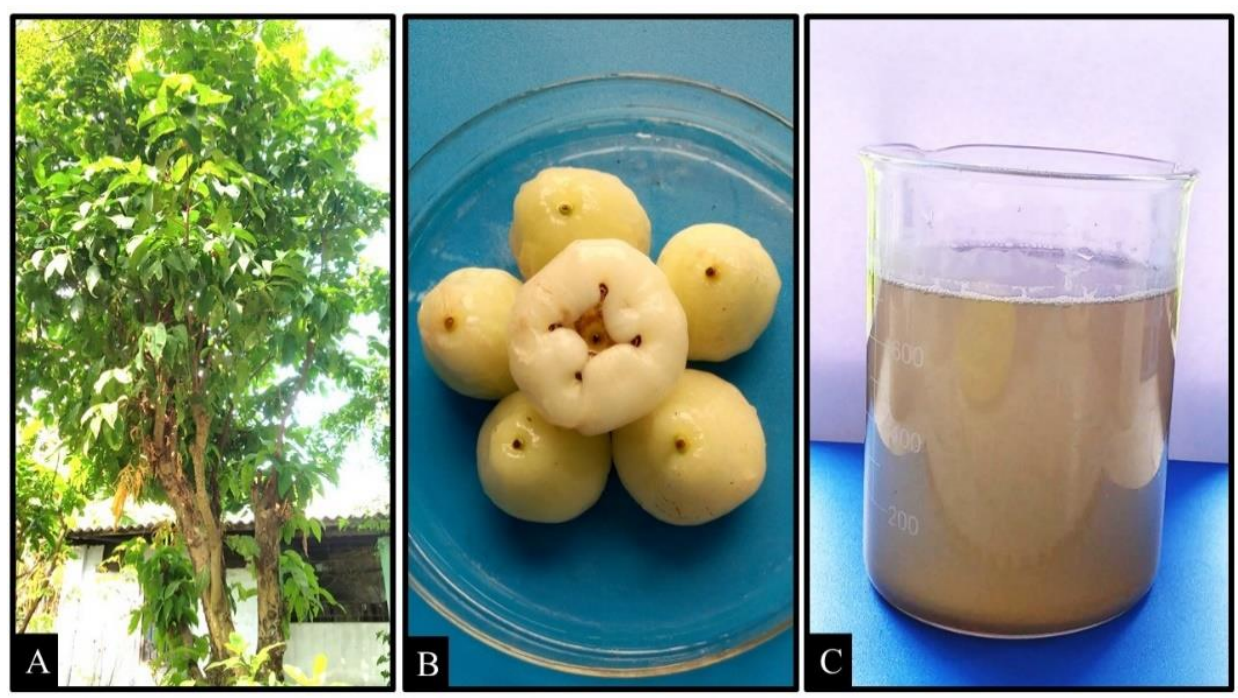

Figure 1. A. Wax apple or Syzygium samarangense tree, B. Fresh Syzygium samarangense fruits or wax apples (white wax apple or jamrul), C. Handmade wax apple juice from freshly harvested fruits

Table 1. Methods and results of qualitative chemical tests

\begin{tabular}{|c|c|}
\hline Phytochemicals & Qualitative detection method \\
\hline Flavonoids & $\begin{array}{l}\text { Few drops of } 10 \% \mathrm{FeCl}_{3} \text { solution was added to } 1 \mathrm{~mL} \text { of sample. A green or blue color would indicate the } \\
\text { presence of flavonoids. }\end{array}$ \\
\hline Tannin & $\begin{array}{l}\text { To } 0.5 \mathrm{~mL} \text { sample and few drops of } \mathrm{HNO}_{3} \text { was added. The reddish to yellow color of the solution would indicate } \\
\text { the presence of tannins. }\end{array}$ \\
\hline Cardiac glycosides & $\begin{array}{l}0.5 \mathrm{~mL} \text { of sample were evaporated and dissolved in } 1 \mathrm{~mL} \text { glacial acetic acid. } 1 \text { drop of } 10 \% \mathrm{FeCl} 3 \text { solution } \\
\text { followed by } 1 \mathrm{~mL} \text { of Conc. } \mathrm{H}_{2} \mathrm{SO}_{4} \text { was added by the side of test tube. Appearance of brown color rings at the } \\
\text { interface would indicate the presence of cardiac glycosides. }\end{array}$ \\
\hline Protein & $\begin{array}{l}1 \mathrm{~mL} \text { of } 4 \% \mathrm{NaOH} \text { solution and a few drops of } 1 \% \mathrm{CuSO} 4 \text { solution were added to } 3 \mathrm{~mL} \text { of sample solution. A } \\
\text { violet or pink color would indicate presence of protein. }\end{array}$ \\
\hline Coumarin & $\begin{array}{l}\text { Few drops of } \mathrm{NaOH} \text { solution was added to } 1 \mathrm{~mL} \text { of sample. Yellow coloration would indicate the presence of } \\
\text { coumarin }\end{array}$ \\
\hline Terpenoid & $\begin{array}{l}50 \mu \mathrm{L} \text { sample was evaporated. The remaining was dissolved in chloroform and concentrated } \mathrm{H} 2 \mathrm{SO} 4 \text { was added } \\
\text { from the sidewall of test tubes. Formation of red to reddish-brown coloration at the base would confirm the } \\
\text { presence of terpenoids. }\end{array}$ \\
\hline Steroid & $\begin{array}{l}\text { For test of } 0.5 \mathrm{~mL} \text { samples were evaporated and dissolved in } 2 \mathrm{~mL} \text { chloroform. } 2 \mathrm{~mL} \text { of Conc. } \mathrm{H}_{2} \mathrm{SO}_{4} \text { was } \\
\text { introduced carefully by the sidewall of the test tube. Formation of red color ring would confirm the presence of } \\
\text { steroid. }\end{array}$ \\
\hline Phenol & $\begin{array}{l}5 \mathrm{mg} \mathrm{FeCl}_{3} \text { was added to } 1 \mathrm{~mL} \text { of sample, followed by vigorous shaking. Green coloration would indicate the } \\
\text { presence of Phenol }\end{array}$ \\
\hline Starch & $\begin{array}{l}\text { Iodine solution wax added drop by drop into the sample. Dark blue coloration would indicate the presence of } \\
\text { starch. }\end{array}$ \\
\hline Reducing sugar & $\begin{array}{l}\text { Benedict's reagent was added to the sample, heated and it turns yellowish-orange. The final color would confirm } \\
\text { the presence of reducing sugar. }\end{array}$ \\
\hline
\end{tabular}

\section{Data analysis}

The data obtained from GCMS analysis were further analyzed by studying available literature. Biosynthesis pathways of metabolites have been discussed and a probable GC-MS based pathway of WAJ metabolites has been proposed after studying literature and KEGG PATHWAY database (Majumder et al. 2020).

\section{Spectrophotometric investigation}

UV-visible absorbance spectrum analysis is a very preliminary spectrum-based compound determination analysis unlike GC-MS (which is scientifically more profound), but here, this spectrophotometric absorbance spectrum was taken into consideration as a cross-check strategy to determine presence of the only major compound of WAJ i.e. hexadecane. Protocols described by Pektaş et al. (2009) and Smith et al. (1967) were followed in this experiment with a slight modification. For comparison marketed hexadecane (Sigma Aldrich, Germany) was used. Samples were prepared following the same concentration where hexadecane (pure) being finely soluble in diethyl ether was dissolved in the targeted solvent and WAJ was 
also extracted with diethyl ether (fresh juice was not used for being a waterbased sample). After zeroing with diethyl ether, absorbance spectrum of the samples was taken (200$800 \mathrm{~nm}$ wavelength) using Cary $60 \mathrm{UV}-\mathrm{V}$ is Spectrometer (Agilent) and graphs were obtained thereafter.

\section{RESULTS AND DISCUSSION}

\section{Qualitative chemical tests}

Qualitative tests can provide an idea about presence of valuable groups of organic molecules in test sample. Where none of the organic groups like tannin, coumarin, cardiac glycosides, steroid, terpenoids, flavonoids, phenol, proteins, and starch were detected in fresh juice of WAJ except reducing sugar. Juice of any tropical fruit juices usually contains flavonoids or phenolic acids that confer free radical scavenging activity to a great extent, so, it was quite surprising that fruit juice of wax apple tested completely negative for the presence of those components.

\section{Antioxidant activity (DPPH assay)}

DPPH free radical scavenging activity of fresh WAJ resulted in 55.59 $\pm 0.819 \mu \mathrm{g} \mathrm{AAE} / \mathrm{mL}$ (Ascorbic acid equivalent where IC50 value is 43.11). Previous studies on fruit juices are considered (described in the discussion section) then our experiment on WAJ definitely showed very low level of inhibition which actually has supported the low antioxidant activity of the fruit juice.

\section{Antibacterial test}

No visible inhibition zone was found in the plates after three repeated tests which confirmed that WAJ has no significant antibacterial property against these bacterial samples.

\section{Gas chromatography-mass spectrometry analysis and metabolomics}

Gas chromatography-mass spectrometry analysis of WAJ dissolved in methanol revealed presence of six different compounds. The chromatogram of GC-MS showing peaks is depicted in Figure 2 and Table 2.

Out of the six compounds detected by GC-MS, only three compounds (hexadecane; dibutyl phthalate or DBP; and elaidic acid, methyl ester) are found to have potential bioactive properties. Detected compounds trans-1-hexanoyl2-(1-(phenylseleno)-1-(trimethylsilyl) methyl-cyclopropane and cyclododecasiloxane, tetracosamethyl are reported contaminations (GC-MS contaminants) from the column bleeding and siloxane is a column matrix component along with silyl, silane, siloxyl- are derivatives. So, hexadecane, a long chain alkane or wax is the only abundant compound with $77.26 \%$ peak area here (mass spectrum is given in Figure 3). Elaidic acid, methyl ester is a bioactive unsaturated omega- 9 fatty acid ester and trans-isomer of oleic acid which is a food component also (National Center for Biotechnology Information 2021). Elaidic acid, methyl ester also consists of long-chain and these types of longchain fatty acid esters are also considered as waxy components (Whitaker et al. 2001). 5-Tetradecyne was also detected with a minor area in GC-MS analysis 5-tetradecyne is a long chain alkyne hydrocarbon which is also a wax. Biosynthesis pathways of WAJ waxes (hexadecane and elaidate) have been studied and a pathway has been proposed which is based on KEGG pathway database and other reviewed literature and general rules of phytochemical synthesis and has been described in the section 'Discussion' section.

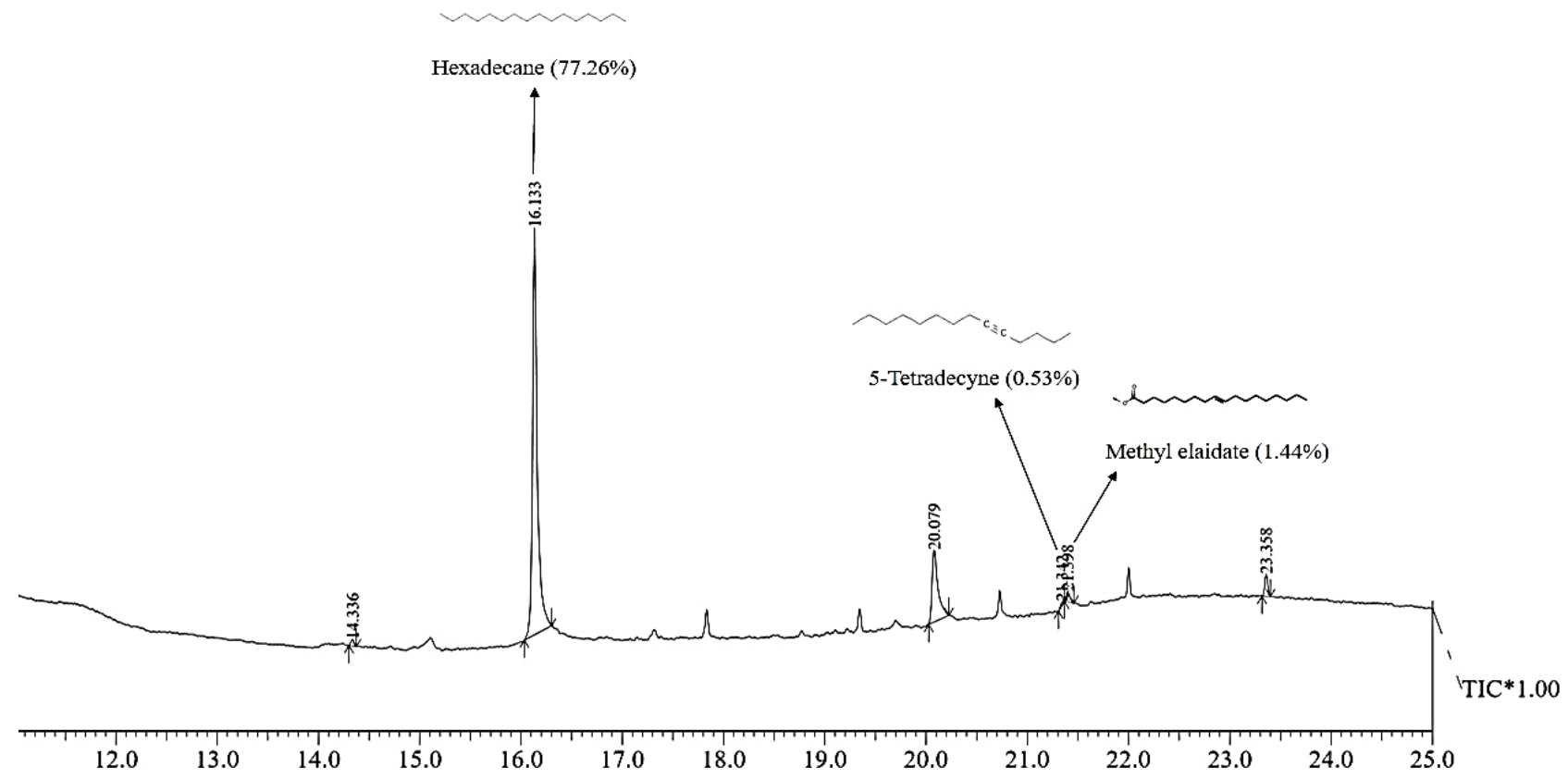

Figure 2. GC-MS chromatogram of WAJ showing peaks of waxes like hexadecane, 5-tetradecyne and methyl elaidate 
Table 2. GC-MS derived compounds in WAJ

\begin{tabular}{crlrl}
\hline Peak no. & R. Time & Area & Area\% & Name \\
\hline 1 & 14.336 & 27387 & & \\
2 & 16.133 & 2820658 & 0.75 & Trans-1-hexanoyl-2-(1-(phenylseleno)-1-(trimethylsilyl)methyl)cyclopropane \\
3 & 20.079 & 632605 & 17.33 & Hexadecane \\
4 & 21.342 & 19472 & 0.53 & 5-Tetradecyne \\
5 & 21.398 & 52550 & 1.44 & Elaidic acid, methyl ester \\
6 & 23.358 & 98260 & 2.69 & Cyclododecasiloxane, tetracosamethyl \\
& & 3650932 & 100 & \\
\end{tabular}

\section{Spectrophotometric determination of hexadecane}

Both images of the absorbance spectrums obtained after the analysis are given in Figure 4 which, being finely and parallel overlapped, has clearly indicated that both WAJ and hexadecane have very much similarities. A slight dissimilarity is visible because raw WAJ contains not only hexadecane but also other hydrocarbons or fatty acids (detected in GC-MS). But, the level of accuracy with the graph of hexadecane (pure) shown by raw WAJ definitely proves the majority of hexadecane in it.

\section{Discussion}

Antioxidants have diverse role to play in the life of organisms by maintaining a balance between pro-oxidation and anti-oxidation (Bhattacharya and Chakraborty 2015). After assessing and observing all the preliminary phytochemical experiments like qualitative test, anti-oxidant assay, and antibacterial test, it was confirmed that this fruit juice has no such significant bioactivity. Previously, many scientists (Rekha et al. 2012; Zou et al. 2016) have done profound research on fruit juices and their antioxidant properties which has helped in this research to evaluate the antioxidant property of WAJ in a comparative way and according to those previous studies, DPPH scavenging value of $5.5 \mathrm{mg}$ AAE by $100 \mathrm{~mL}$ of a juice is very much low. Moreover, absence of important bioactive groups in WAJ such as, flavonoids, phenols, cardiac glycosides and coumarins, is also proportional to its antioxidant and antibacterial activity. So, finally, a GC-MS-based metabolomic study became needful to know about the phytochemicals or the metabolites present in this fruit juice which might help to investigate the low bioactivity of WAJ at a molecular level. In previous research, Khandaker et al. (2015) conducted antioxidant, antimicrobial and other biochemical tests for three cultivars of wax apple, where red and pink wax apple showed significantly higher bioactivity compared to green giant cultivar (white wax apple). This research conforms to our findings.

GC-MS analysis solved our confusion regarding low in vitro bioactivity was resolved. All the results are parallel to the results for the preliminary tests where no significant antioxidant or antimicrobial activity was detected. But, what was found, was only some huge peaks of compounds biosynthesized through wax biosynthesis pathway. Actually, in nature, long chains of alkanes, alkynes, fatty acids, esters (mainly hydrocarbons with long aliphatic alkyl chains), etc. are considered waxes. So, components like hexadecane, elaidate and 5-tetradecyne detected in WAJ are the waxes of wax apple juice. Being the major component, it is justified that hexadecane is the main wax of wax apple and it should be the reason behind mentioning the word wax before this fruit's name. Hexadecane is a liquid wax, viscous in nature. Alkanes are saturated hydrocarbons and chemically very inert or less reactive as they are apolar molecules (Labinger and Bercaw 2002; Singh et al. 2012) but, they can be broken down into potential bioactive forms (mainly fatty acids) under the influence of microorganism (Singh et al. 2012). It is reported that microbial biodegradation of hexadecane (Volke-Sepulveda et al. 2003) is the only probable way where bio-active components like hexadecanol, hexadecanal, hexadecanoic acid, etc. are synthesized from the compound. Other waxes like methyl elaidate (long-chain fatty acid ester) and 5-tetradecyne (long-chain alkyne) were also found but detected in a minute quantity in this research. Interestingly, fatty acid esters and long-chain hydrocarbons have a close physicochemical affinity with natural waxes in nature as fatty acid esters like oleates, elaidates and palmitates are often found in beeswax (Buchwald et al. 2009; Tulloch 1980) along with alkanes (WAJ compound hexadecane) and alkynes (WAJ compound 5-tetradecyne). Other than beeswax, there are several examples regarding plants or vegetable wax where cuticular or epicuticular wax, seed oil extracts, fruit coatings, etc. are reported to contain several long-chain hydrocarbons along with fatty acids esters (Seigler 1998; Majumder et al. 2020a). So, wax apple is not going to be the only example here. Furthermore, none of the detected natural compounds of WAJ has any flavor which also justifies the flavorlessness of wax apple. 


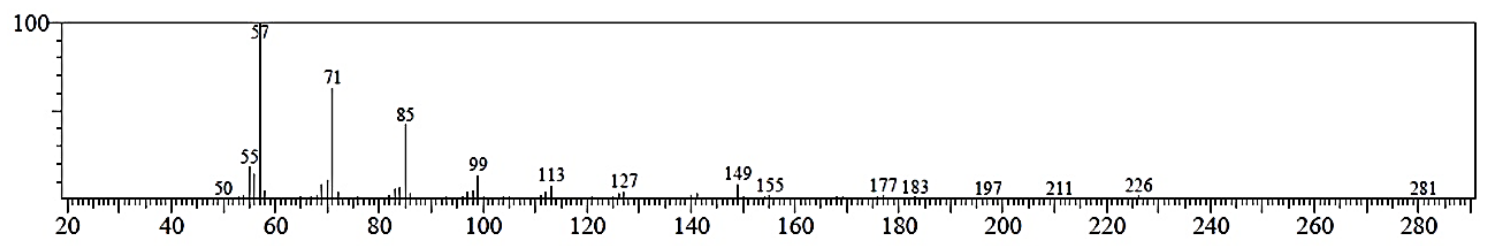

GC-MS mass spectrum of hexadecane in WAJ

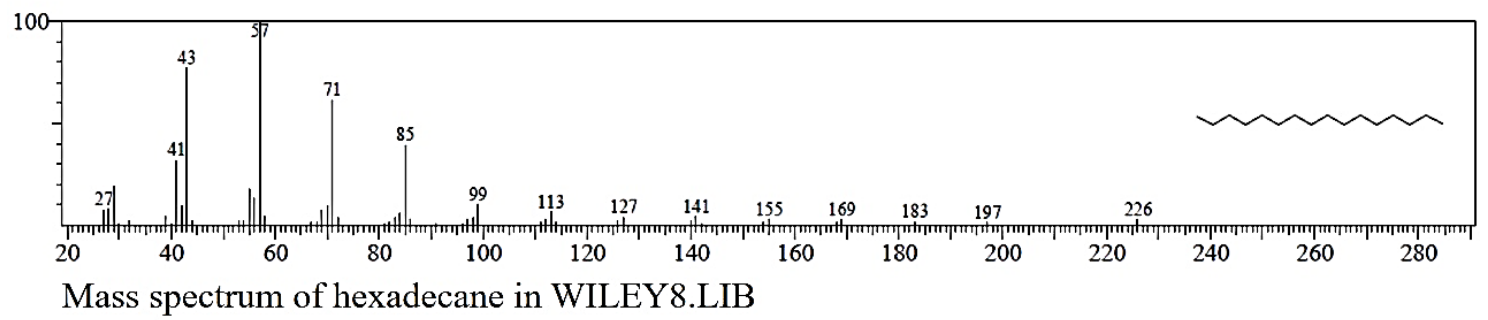

Figure 3. GC-MS mass spectrum of major WAJ compound hexadecane

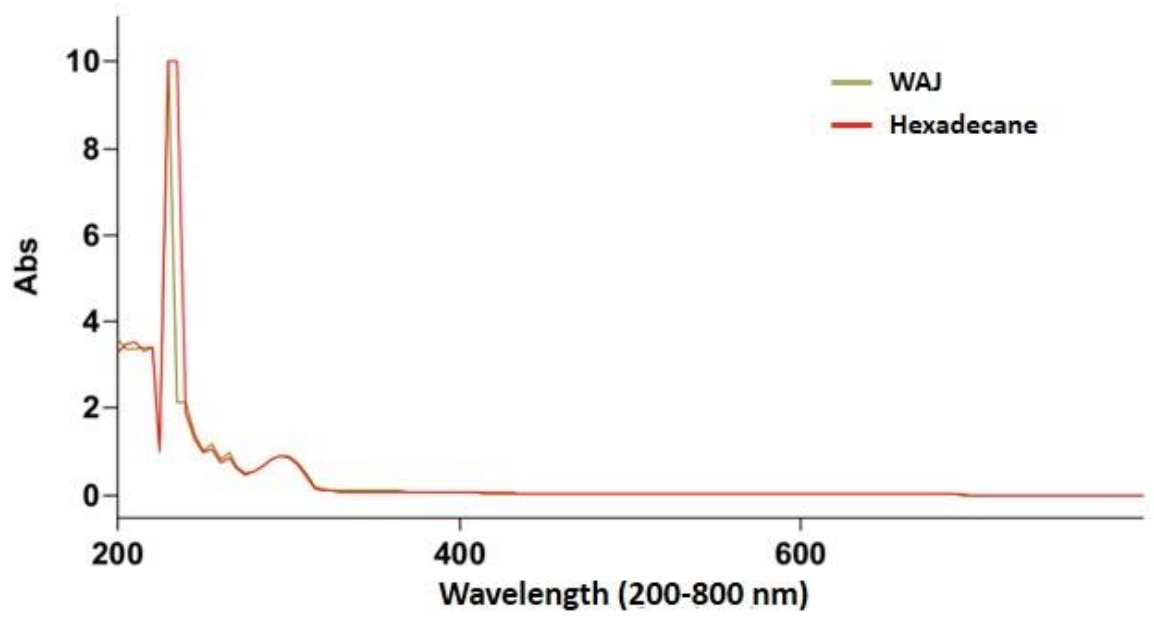

Figure 4. UV-visible spectrum of hexadecane and WAJ

Biosynthesis pathway of wax like long-chain alkanes, alkynes, fatty acids, their esters, etc. are established in KEGG (Kyoto Encyclopedia of Genes and Genomes) database (KEGG 2021) where unsaturated fatty acids after biosynthesis and elongation produce metabolites such as elaidates (C18) or other long-chain fatty acids, wax esters and hexadecane (long-chain alkanes), etc. Wax biosynthesis generally begins with unsaturated fatty acid biosynthesis in the plastid. Then after fatty acid elongation (FAE), longchain fatty acids like C16 (palmitic acid), C18 (oleic acid or elaidic acid), C22 (docosanoic acid) or very long chains (C24-C34) are synthesized, and parallely elongated products like several alkanes, secondary alcohols, ketones, primary alcohols and wax esters are produced (KEGG 2021; Kunst and Samuels 2003). Interestingly, two wax components of WAJ, hexadecane and elaidic acid, methyl ester are intermediates of the same pathway which has no report to date but follows the general wax biosynthesis pathway and theoretically possible if nature of reactions is concerned. In between synthesis of elongated long-chain fatty acid through and synthesis of fatty acyl-CoA, fatty acid oxidation occurs on the outer mitochondrial membrane by acyl-CoA synthetase where one molecule of coenzyme A and one molecule of adenosine triphosphate (ATP) are used (Oxidation of Fatty Acids 2020). Then, oxidation of the fatty acyl-CoA occurs in the mitochondrial matrix via a sequence of reactions known as $\beta$-oxidation. Moreover, production of heptadecanal (a probable precursor of hexadecane) from acyl Co-A of an octadecanoic acid is reported in living organisms (Foulon et al. 2005) while synthesis of odd chain fatty acid (C-17, a probable precursor of hexadecane) from even chain (C-18) is also established (Jenkins et al. 2015), but in bacteria. However, in plant wax biosynthesis pathway the fatty acyl Co-A is converted into long-chain aldehydes, alkanes, secondary alcohols and ketones respectively through a series of decarbonylation reactions which involves loss of CO, thus, the number of carbon seems to be decreased one by one from the chain. But, there is no reported pathway to define formation of hexadecane from elaidic acid, so, Figure 5 is proposed. Previously reported decarbonylation reactions like, formation of heptadecane from octadecanal (Cheesbrough and Kolattukudy 1984) in plants or formation 
of hexadecane from heptadecanal (Foo et al. 2017) in microorganisms can also support this GC-MS metabolomics based probable pathway describing possibilities of formation of hexadecane from elaidic acid (an octadecanoic acid) through enzymatic reaction. Scientist Kunst and Samuels (2003) have done a profound study on this pathway, mainly cuticular wax biosynthesis pathway. According to their research, from fatty acid synthesis to formation of $\mathrm{C} 18$ (octadecanoic acids) takes place in plastid while fatty acid elongation to very long-chain fatty acid (VLCFA) formation occurs in endoplasmic reticulum (ER). Furthermore, acyl reduction and decarbonylation reactions occur on domains of the ER (associated with plasma membrane) and finally deposited in the cell wall as cuticular waxes. Generally, regarding aliphatic natural wax components, their class and site of synthesis depend on the chain length like n-alkanes, secondary alcohols, ketones, fatty alcohols, long-chain fatty acids, VLCFA, aldehydes and wax esters where WAJ component elaidic acid (C18) is a long-chain fatty acid (not VLCFA) and hexadecane (C16) is an alkane (not VLC alkane). According to previous reports, it is highly likely that enzyme decarbonylase is located in the cell wall matrix (Cheesbrough and Kolattukudy 1984; Kunst and Samuels 2003) and this proposed pathway also supports the activity of decarbonylase as a C18 fatty acid is detected which is suggested to be the precursor of the major product i.e., a C16 alkane. Moreover, the presence of hexadecane and the majority of this liquid wax in wax apple also suggest that no more fatty acid elongation (VLCFA synthesis) occurred after synthesizing the only detected $\mathrm{C} 18$ fatty acid. So, decarbonylation occurred in wax apple soon after C18 fatty acid synthesis in plastid which blocked synthesis of farther VLCFAs or wax esters. However, according to Yeats and Rose (2013), the enzymatic basis of alkane synthesis is still a long unresolved question, mainly for long-chain alkanes (non-VLC) while microbial biosynthesis of alkanes from C18 fatty acids is more established. Brown et al. (2019) have done an extensive study on microbial biosynthesis of alkane where $\mathrm{C} 25-\mathrm{C} 33$ range has been categorized as VLC alkanes and shorter alkanes (like C16 or hexadecane of WAJ) as mid-chain alkanes. According to their study, biosynthesis of alkanes in eukaryotic cells occur directly from C12, C14, $\mathrm{C} 16, \mathrm{C} 18$, and $\mathrm{C} 20$ saturated fatty acids through enzymatic decarboxylation by OleT or fatty acid decarboxylase (Belcher et al. 2014; Brown et al. 2019). But, some recent research articles (Sorigué et al. 2017; Huijbers et al. 2018) have described enzyme fatty acid decarboxylase activity in eukaryotes (in photosynthetic algae) has increased the accuracy of this proposed alkane biosynthesis pathway from C18 fatty acids. It is reported that in the chloroplast membrane of microalgae Chlorella and Chlamydomonas, fatty acid photo decarboxylase (FAP) converts exogenous fatty acids to alkanes (Sorigué et al. 2017). The proposed biosynthetic route of WAJ wax is very simple and has been adapted from KEGG pathway database and other literature described earlier (given in Figure 5).

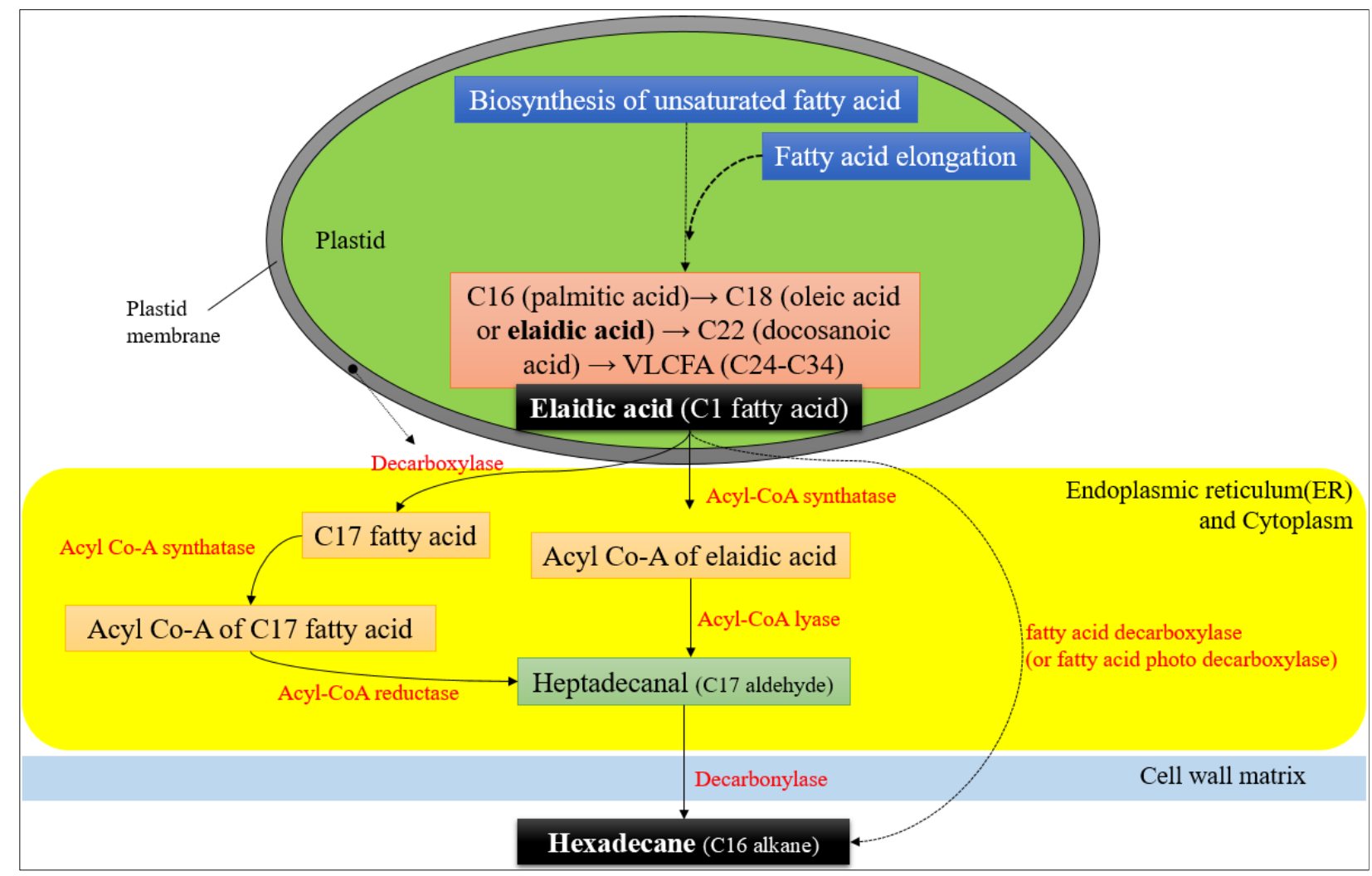

Figure 5. Proposed biosynthesis pathway of the WAJ metabolome (Wax) 
Source of DBP (another major compound of WAJ) in wax apple juice is confusing because it has been already reported as contamination from lab wares (Majumder et al. $2020 \mathrm{~b}$ ) and the probable reason for presence of phthalate in WAJ can be its exposure to laboratory materials like Eppendorf tubes, beaker, GC-MS machinery, etc. However, DBP is reported as highly bioactive (antioxidant, antibacterial) glucose-derived component (Zhang et al 2018) from shikimic acid pathway. While, results and observations of qualitative chemical tests antioxidant and antibacterial tests, GC-MS metabolomics-based pathway studies and spectrophotometric evaluation, etc. oppose the occurrence of DBP in WAJ. Although, presence of reducing sugar suggests chemical reactions for synthesis of dibutyl phthalate from sugars (glucose) of fresh WAJ as none of any sugar-derived compound was detected in GC-MS, but due to lacking strong reports it cannot be considered.

Reportedly, wax apple is useful in diseases like dysentery or diarrhea and, interestingly, revealed metabolites of WAJ also support this health claim. After assessing GC-MS analysis and spectrophotometric evaluation, presence of huge amount of hexadecane in this fruit juice has been proven which, being viscid or gelatinous liquid in nature, may definitely be the reason behind antidiarrheal activity. Moreover, elaidate is known to increase plasma cholesteryl ester transfer protein (CETP) activity which lowers HDL cholesterol (Abbey and Nestel 1994). But, presence of the compound in very minute amount, showing negative results in all of the above in vitro phytochemical tests and absence of major phytochemical groups surely demote the medicinal value of WAJ by giving the "low bioactive" tag on it. Absence of bioactive groups of molecules, low in vitro antioxidant activity, absence of inhibition zones in antimicrobial assays, abundance of wax compound hexadecane, and design of unexplored biosynthesis pathway of wax apple's wax biosynthesis through metabolomics; are the key findings of this study. The outcome of this research and evidence of microbial biodegradation of hexadecane may increase the utility of wax apple by using this low bioactive fruit in different research areas like fermentation biotechnology where biodegradation can convert this low bioactive substrate into various bioactive forms. Moreover, this research suggests that bioactive potentiality of any plant cannot be depended only on results of biochemical assays, metabolomics can play the role of an important parameter to judge acceptability of any underutilized product. Both Masam manis pink and Jambu madu red are reported as better in quality regarding yield, flavor and functional uses unlike the giant green cultivar (greenish-white wax apple) which was chosen for this study because of its availability and significance as a native cultivar in our study area (subHimalayan plains of West Bengal, India). Research on genetics and ecology of this plant are imperative to resolve the dilemma. Large quantity of hexadecane found in plant can be explored for beneficial purposes.

\section{ACKNOWLEDGEMENTS}

The authors would like to acknowledge the help received from tea garden workers during collection and their contribution to good maintenance of wax apple trees in the garden. Authors have no potential conflicts of interest.

\section{REFERENCES}

Abbey M, Nestel PJ. 1994. Plasma cholesteryl ester transfer protein activity is increased when trans-elaidic acid is substituted for cis-oleic acid in the diet. Atherosclerosis 106 (1): 99-107. DOI: 10.1016/00219150(94)90086-8.

Amor EC, Villasenor IM, Yasin A, Choudhary MI. 2004. Prolyl endopeptidase inhibitors from Syzygium samarangense (Blume) Merr. \& L. M. Perry. Z. Naturforsch 59c: 86-92. DOI: 10.1515/znc-2004-1218.

Belcher J, McLean KJ, Matthews S, Woodward LS, Fisher K, Rigby SE, Nelson DR, Potts D, Baynham MT, Parker DA, Leys D. 2014. Structure and biochemical properties of the alkene producing cytochrome P450 OleTJE (CYP152L1) from the Jeotgalicoccus sp. 8456 bacterium. J Biol Chem 289 (10): 6535-50. DOI: 10.1074/jbc.M113.527325.

Bhattacharya M, Chakraborty S. 2015. Free radicals and naturally occurring antioxidants. J Pharm Phytochem 3: 1-7.

Bhattacharya M, Mandal P, Sen A. 2009. In vitro detection of antioxidants in different solvent fractions of Ginger (Zingiber officinale Rosc.). Indian J Plant Physiol 14 (1): 23-27.

Brown S, Loh J, Aves S, Howard T. 2019. Alkane Biosynthesis in Bacteria. Springer. DOI: 10.1007/978-3-319-78108-2_7.

Buchwald R, Breed MD, Bjostad L, Hibbard BE, Greenberg AR. 2009. The role of fatty acids in the mechanical properties of beeswax. Apidologie 40 (5): 585-594. DOI: 10.1051/apido/2009035.

Chakraborty S, Majumder S, Ghosh A, Saha S, Bhattacharya M. 2021. Metabolomics of potential contenders conferring antioxidant property to varied polar and non-polar solvent extracts of Edgaria darjeelingensis CB Clarke. Bull Natl Res Centre 45 (1): 1-12. DOI: 10.1186/s42269-021-00503-3.

Cheesbrough TM, Kolattukudy PE. 1984. Alkane biosynthesis by decarbonylation of aldehydes catalyzed by a particulate preparation from Pisum sativum. Proc Natl Acad Sci 81 (21): 6613-6617. DOI: 10.1073/pnas.81.21.6613.

Das AK, Ghosh A, Majumder S, Saha S, Acharyya S, Sarkar S, Chakraborty S, Mukherjee M, Bhattacharya M. 2020. Characterization of tea and tea infusion: A study of marketed black tea samples from some teagrowing regions of India. J Pharm Phytochem 9 (5): 1532-1540. DOI: 10.22271/phyto.2020.v9.i5v.12553.

Foo JL, Susanto AV, Keasling JD, Leong SSJ, Chang MW. 2017. Wholecell biocatalytic and de novo production of alkanes from free fatty acids in Saccharomyces cerevisiae. Biotechnol Bioeng 114 (1): 232-237. DOI: 10.1002/bit.25920.

Foulon V, Sniekers M, Huysmans E, Asselberghs S, Mahieu V, Mannaerts GP, Van Veldhoven PP, Casteels M. 2005. Breakdown of 2hydroxylated straight chain fatty acids via peroxisomal 2hydroxyphytanoyl-CoA lyase: a revised pathway for the $\alpha$-oxidation of straight chain fatty acids. J Biol Chem 280 (11): 9802-9812. DOI: 10.1074/jbc.M413362200.

Fruitsinfo, 2004-2021. https://www.fruitsinfo.com/Wax-jambu-Exoticfruits.php. Accessed on 2 April 2021.

Gayen PR, Al Hossain AM, Saifuzzaman M, Faroque ABM. 2016. Anthelmintic activity of ethanolic extract of Syzygium samarangense (Blume) Merril \& Perry. Dhaka Univ J Pharm Sci 15(1): 109-111. DOI: 10.3329/dujps.v15i1.29204.

Ghayur MN, Gilani AH, Khan A, Amor EC, Villasenor IM, Choudhary MI. 2006. Presence of calcium antagonist activity explains the use of Syzygium samarangense in diarrhoea. Phytother Res 20: 49-52. DOI: 10.1002/ptr.1801

Ghosh A, Majumder S, Saha S, Bhattacharya M. 2020. Characterization of nonpolar and polar solvent extracts from some tea plantation shade tree leaves with special reference to antioxidant and antibacterial activities. Res Plant Biol 10: 15-21. DOI: 10.25081/ripb.2020.v10.6235.

Huijbers MM, Zhang W, Tonin F, Hollmann F. 2018. Light-driven enzymatic decarboxylation of fatty acids. Angewandte Chemie Int Edition 57 (41): 13648-13651. DOI: 10.1002/anie.201807119.

Jenkins B, West JA, Koulman A. 2015. A review of odd-chain fatty acid metabolism and the role of pentadecanoic acid (C15: 0) and 
heptadecanoic acid (C17: 0) in health and disease. Molecules 20 (2): 2425-2444. DOI: 10.3390/molecules20022425.

KEGG. 2021. KEGG: Kyoto Encyclopedia of Genes and Genomes. Accessed April 2, 2021. https://www.genome.jp/kegg/pathway.html

Khandaker MM, Boyce AN. 2016. Growth, distribution and physiochemical properties of wax apple ('Syzygium samarangense'): A review. Aust J Crop Sci 11 (12): 1640. DOI: 10.21475/ajcs.2016.10.12.PNE306.

Khandaker MM, Sarwar MJ, Mat N Boyce AN. 2016. Bioactive constituents, antioxidant and antimicrobial activities of three cultivars of wax apple (Syzygium samarangense L.) fruits. Res J Biotechnol 10 (1): 7-16.

Kunst L, Samuels AL. 2003. Biosynthesis and secretion of plant cuticular wax. Prog Lipid Res 42 (1): 51-80. DOI: 10.1016/S01637827(02)00045-0.

Kuo YC, Yang LM, Lin LC. 2004. Isolation and immunomodulatory effect of flavonoids from Syzygium samarangense. Planta Med 70: 1237-39. DOI: $10.1055 / \mathrm{s}-2004-835859$.

Labinger JA, Bercaw JE. 2002. Understanding and exploiting $\mathrm{C}-\mathrm{H}$ bond activation. Nature 417 (6888): 507-514. DOI: 10.1038/417507a

Lim TK. 2012. Syzygium samarangense. In Edible Medicinal and Non Medicinal Plants. Dordrecht, Springer. DOI: 10.1007/978-94-007 2534-8_105.

Majumder S, Ghosh A, Bhattacharya M. 2020. Natural anti-inflammatory terpenoids in Camellia japonica leaf and probable biosynthesis pathways of the metabolome. Bull Natl Res Centre 44 (141): 1-14. DOI: 10.1186/s42269-020-00397-7.

Majumder S, Ghosh A, Chakraborty S, Bhattacharya M. 2020a. GC-MS analysis reveals Dendrobium candidum is a mosquito-attractant orchid with mosquitocidal compounds. Int J Mosq Res 7 (6): 09-12. DOI: 10.22271/23487941.2020.v7.i6a.483

Majumder S, Sarkar S, Ghosh A, Acharyya S, Saha S, Chakraborty S, Bhattacharya M. 2020b. Photosynthetic organs of wild Indian tea tree are rich in patchouli components: a GC-MS based metabolomics. Nat Prod Res 1-5. DOI: 10.1080/14786419.2020.1851222.

Mollika S, Islam N, Parvin N, Kabir A, Sayem MW, Luthfunnesa SR. 2014 Evaluation of analgesic, anti-inflammatory and CNS activities of the methanolic extract of Syzygium samarangense leave. Glob J Pharmacol 8 (1): 39-46.

Morton JF. 1987. Fruits of Warm Climates. JF Morton, Miami, Florida.

National Center for Biotechnology Information. 2021. PubChem Compound Summary for CID 637517, Elaidic acid https://pubchem.ncbi.nlm.nih.gov/compound/Elaidic-acid. Accessed April 2, 2021.

Oxidation of Fatty Acids. 2020 https://chem.libretexts.org/@go/page/234043. Accessed on April 2, 2021.

Pektas G, Dinç E, Baleanu D. 2009. Combined application of continuous wavelet transform-zero crossing technique in the simultaneous spectrophotometric determination of perindopril and indapamid in tablets. Química Nova 32 (6): 1416-1421.

Rekha C, Poornima G, Manasa M, Abhipsa V, Devi JP, Kumar HTV, Kekuda TRP. 2012. Ascorbic acid, total phenol content and antioxidant activity of fresh juices of four ripe and unripe citrus fruits. Chem Sci Trans 1 (2): 303-310. DOI: 10.7598/cst2012.182.

Resurreccion-Magno MH, Villasenor IM, Harada N, Monde K. 2005. Antihyperglycaemic flavonoids from Syzygium samarangense (Blume) Merr. and Perry. Phytother Res 19: 246-251. DOI: 10.1002/ptr.1658.

Reynertson KA, Yang H, Jiang B, Basile MJ, Kennelly EJ. 2008. Quantitative analysis of antiradical phenolic constituents from Syzygium samarangense (Myrtaceae) fruits. Food Chem 109: 883-890. DOI: 10.1016/j.foodchem.2008.01.021.

Seigler DS. 1998. Plant Waxes. In Plant Secondary Metabolism. Springer, Boston, MA. pp. 51-55. DOI: 10.1007/978-1-4615-4913-0 4.

Shahreen S, Banik J, Hafiz A, Rahman S, Zaman AT, Shoyeb MA, Chowdhury MH, Rahmatullah M. 2011. Antihyperglycemic activities of leaves of Syzygium samarangense of Bangladesh. Afr J Tradit Complement Altern Med 9: 287-291. DOI: 10.4314/ajtcam.v9i2.16.

Shen SC, Chang WC, Chang CL. 2013. An extract from wax apple (Syzygium samarangense (Blume) Merrill and Perry) effects glycogenesis and glycolysis pathways in tumor necrosis factor- $\alpha$ treated FL83B mouse hepatocytes. Nutrients 5: 455-467. DOI: $10.3390 /$ nu5020455.

Singh SN, Kumari B, Mishra S. 2012. Microbial degradation of alkanes. In Microbial degradation of xenobiotics. Springer, Berlin. DOI: 10.1007/978-3-642-23789-8 17.

Smith JWG, De Grey GE, Patel VJ. 1967. The spectrophotometric determination of ampicillin. Analyst 92 (1093): 247-252. DOI: 10.1039/an9679200247.

Sorigué D, Légeret B, Cuiné S, Blangy S, Moulin S, Billon E, Richaud P, Brugière S, Couté Y, Nurizzo D, Müller P. 2017. An algal photoenzyme converts fatty acids to hydrocarbons. Science 357 (6354): 903-907. DOI: 10.1126/science.aan6349.

Srivastava R, Shaw AK, Kulshreshtha DK. 1995. Triterpenoids and chalcone from Syzygium samarangense. Phytochemistry 38 (3): 687 689. DOI: 10.1016/0031-9422(94)00739-G.

Tulloch AP. 1980. Beeswax - composition and analysis. Bee World 61 (2): 47-62. DOI: 10.1080/0005772X.1980.11097776.

Volke-Sepulveda TL, Gutiérrez-Rojas M, Favela-Torres E. 2003. Biodegradation of hexadecane in liquid and solid-state fermentations by Aspergillus niger. Bioresour Technol 87 (1): 81-86. DOI: 10.1016/S0960-8524(02)00207-9.

WCSP. 2021. World Checklist of Selected Plant Families. Facilitated by the Royal Botanic Gardens, Kew. http://wcsp.science.kew.org/Accessed on 2 April 2021.

Whitaker BD, Schmidt WF, Kirk MC, Barnes S. 2001. Novel fatty acid esters of p-coumaryl alcohol in epicuticular wax of apple fruit. J Agric Food Chem 49 (8): 3787-3792. DOI: 10.1021/jf010409n.

Yeats TH, Rose JK. 2013. The formation and function of plant cuticles. Plant Physiol 163 (1): 5-20. DOI: 10.1104/pp.113.222737.

Zhang H, Hua Y, Chen J, Li X, Bai X, Wang H. 2018. Organism-derived phthalate derivatives as bioactive natural products. J Environ Sci Health: Part C 36 (3): 125-144. DOI: 10.1080/10590501.2018.1490512

Zou Z, Xi W, Hu Y, Nie C, Zhou Z. 2016. Antioxidant activity of Citrus fruits. Food Chem 196: 885-896. 